\title{
Photosynthesis: Miracle of Organic Life and Its Technologies
}

Siddik Icli

Solar Energy Institute, Ege University, Bornova, Izmir 35100, Turkey

\begin{abstract}
The photochemical reaction of carbon dioxide, nitrogen and water in at our atmosphere, production of amino acids, following protein molecular structures, finally creation of micro-living species, and the birth of plants, animals! These microscopic molecular structures (in rivers, lakes, seas) had given birth to moss on land, further all sorts of plants, animals and human beings, that are called as the Miracle of Universe. Human intelligence has created the Technologies simulating photosynthesis, named as Organic Photo-Electronic Technolojigies of OLED lamps, OFET transistors, OPV photovoltaics, that are now in our daily life. A distinct example is OLED-Organic LED lamps, in mobile phones, Lap-Top computers, colored TVs, and other electronics are now based on OLED technology. Advanced developments on Organic Photo Technologies, now overcome to the employment of inorganic materials of steel, iron etc. that creates huge pollution problems on Earth. The OLEDs, followed by the OPV-Organic Photo Voltaics and OFET-Organic Field Effect Transistors, with nature now entered into all of our electronic systems, capable us replace present inorganic technological systems-tools, and lower the pollution threat on our Earth.
\end{abstract}

Key words: OPV, OLED, OFET, photo synthesls.

\section{Introduction}

The photochemical reaction of carbon dioxide, nitrogen and water in at our atmosphere, gives birth to amino acids, following protein molecular structures, finally creation of micro-living species, and the rise of plants, animals! These microscopic molecular structures (in rivers, lakes, seas) had given birth to moss on land, further all sorts of plants, animals and human beings, that are called as the Miracle of Universe.

hv

$$
6 \mathrm{n} \mathrm{CO}_{2}+6 \mathrm{n} \mathrm{H}_{2} \mathrm{O} \rightarrow\left(\mathrm{C}_{6} \mathrm{H}_{12} \mathrm{O}_{6}\right)_{\mathrm{n}}+\mathrm{O}_{2}+1 \mathrm{~s} 1(\Delta \mathrm{E})
$$

Consumption of fossil fuels over millenia, now had given birth to atmospheric enhancement of heat, variation of seasons and exhaustion of limited energy sources. As a result, conversion of solar energy into electricity is now a most attractive technology. As known, miracle of photosynthesis, provides the energy

Corresponding author: Siddik Icli, Dr., professor, research fields: organic photo-electronic technologies and photo organic chemistry. needs of all living species on our Earth [1, 2].

On the other hand, in last quarter of century, Organic Photo-Electronic Technologies of OLED, OFET, OPV entered rapidly to our daily life [3-5]. A distinct example is OLED-Organic LED lamps. Mobile phones, lap-top computers, colored TVs etc. were based on OLED technology [6]. Of course, these developments on Organic Technologies, are steps to adaption of human kind into nature, leaving the employment of steel, iron and birghtons our future centuries [1]. The OLEDs and following the OPV-Organic Photo Voltaics and OFET-Organic Field Effect Transistors, entering into all of our electronic systems, enable us compatability of our technological systems-tools into nature, and our Earth will not be threatened by poisonous waste.

\section{Discussion}

Photosynthesis is not just about oxygen production it is also about energy production. Most people would agree that photosynthesis is a great thing. I have never heard anyone argue against it. However, some folks 
have missed the purpose of photosynthesis. It is not oxygen production. The primary function of photosynthesis is to convert solar energy into chemical energy and then store that chemical energy for future use. For the most part, the planet's living systems are powered by this process. It is not particularly efficient by human engineering standards, but it does the job. Photosynthesis happens in regions of a cell called chloroplasts. The chemistry and physics are complex. It is a bit humbling to consider that the energy in our bodies travels 93 million miles in a little more than eight minutes, and that life has tapped into that energy stream. For a short time that energy is tied up in biological systems before it continues on its merry way into the dark of space. In essence, green plants take carbon, hydrogen and oxygen from the molecules of carbon dioxide and water, and then recombine them into a new molecule called glucose (Fig. 1). This happens in the presence of sunlight, of course. Energy is stored in the bonds of the glucose molecule of $\mathrm{C}_{6} \mathrm{H}_{12} \mathrm{O}_{6}$.

On the other hand, at the process of respiration of living organic species, the glucose molecules break apart under solar irradiation (Fig. 2). Respiration occurs in the cells of nearly all living things. The released energy is then used for all sorts of metabolic activity. Respiration happens in regions of a cell called mitochondria. Mitochondria's main role in the cell is to take glucose, and use the energy stored in its chemical bonds to make ATP in a process called cellular respiration. The chemical reactions are the reverse of photosynthesis, using a glucose molecule and six oxygen molecules (12 atoms) as inputs. Energy is released along with some carbon dioxide and water. Trees and other green plants practice respiration, too, just like animals, but they also practice photosynthesis. This is why ecologists categorize green plants as "producers" and most every other life form as a "consumer." It is about the energy. Oxygen is a byproduct of photosynthesis and,

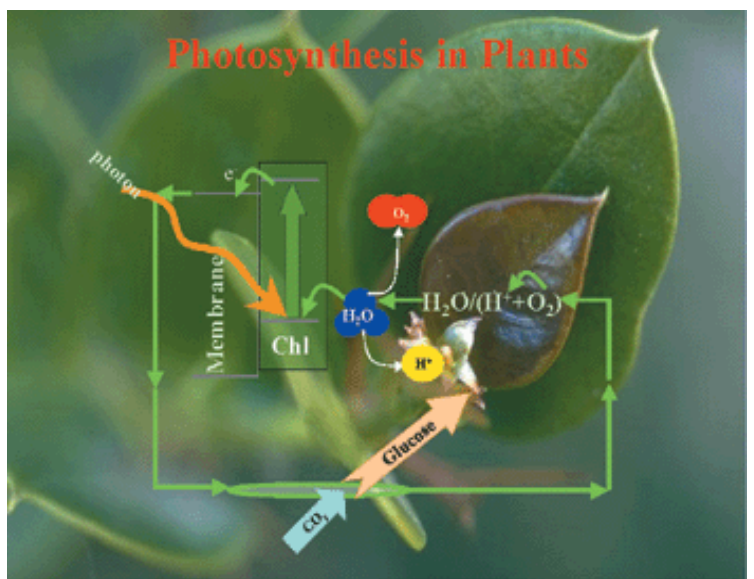

Fig. 1 Mechanism of photosynthesis on plants.

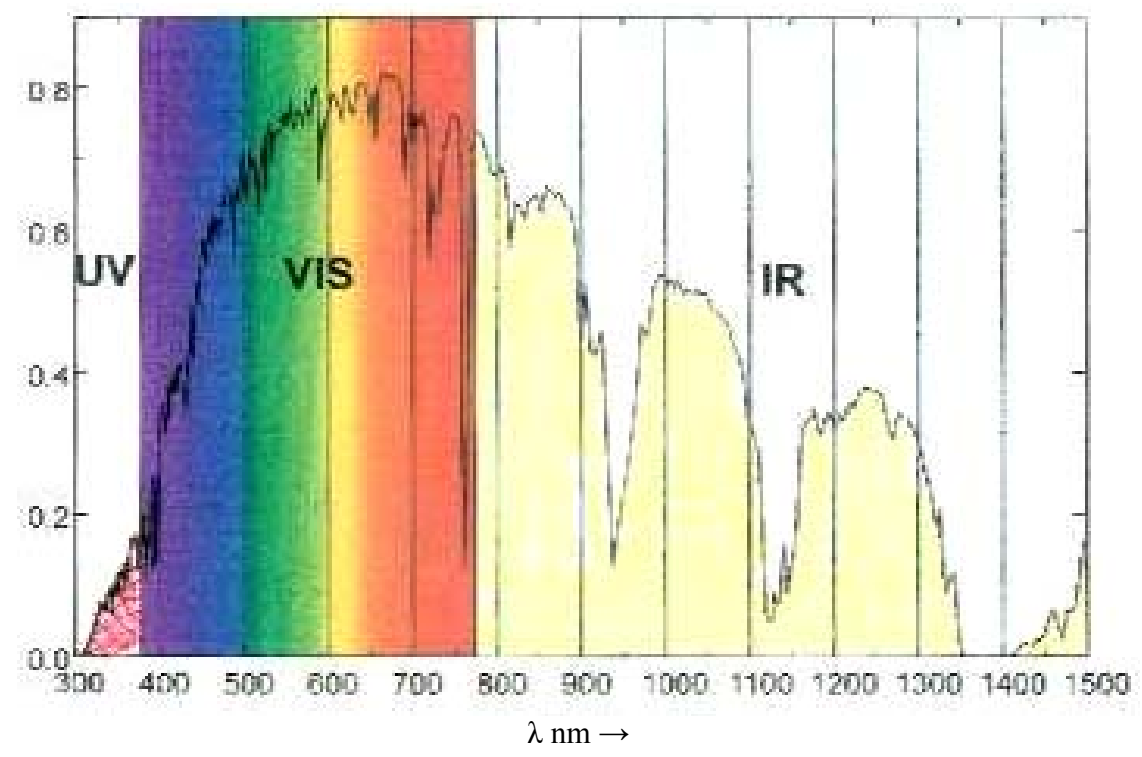

Fig. 2 Solar spectrum. 
correspondingly, carbon dioxide the byproduct of respiration. Trees are often credited as the major oxygen generator for the planet. But most of the planet is covered with water and the collective photosynthesis of lowly algae is the true oxygen machine. Nevertheless, trees and forests are, indeed, significant oxygen producers.

Much of the basic structural material of plants and wood is cellulose, which is an especially complex sugar. The constituent molecules of carbon, hydrogen and oxygen can be recombined to form lots of useful chemicals such as ethanol, perfumes, bioplastics, clothing fabrics and a range of industrial ingredients. It is generally agreed that sources from within renewable living ecosystems have distinct advantages over using the ancient materials that make up fossil fuels. Plants and photosynthesis are the basis of fossil fuels, too, but from millions and millions of years ago (Fig. 3). Trees, forests, forest soils and forest products are mighty important in the cycling of carbon and the relative size of various carbon pools. There are other elements that also cycle through in forests. As for photosynthesis itself, maybe it is better if we think more about the energy capture and less about the oxygen production.

\section{OPVs (Organic Photo Voltaics)}

OPVs (organic photo voltaics), are classified as polymer based OPVs (Table 1) and mono-molecular dye based-DSSCs (Fig. 4). DSSC and OPV are now compatible with the semiconductor metal oxide photovoltaics of $\mathrm{SnO}, \mathrm{ZnO}$ and $\mathrm{Nb}_{2} \mathrm{O}_{5}$ (Table 1).

Almost two decades earlier, DSSCs (dye sensitized solar cells) were proposed as low-cost alternatives to the conventional amorphous silicon solar cells, owing to the simplicity of their fabrication procedures, practically under ambient conditions with mild chemical processes $[1,2]$. DSSCs are placed in the category of third generation photovoltaics where new trends in the photovoltaic technology are applied. One of the basic components of the DSSCs is the photosensitizer which is responsible for the visible and

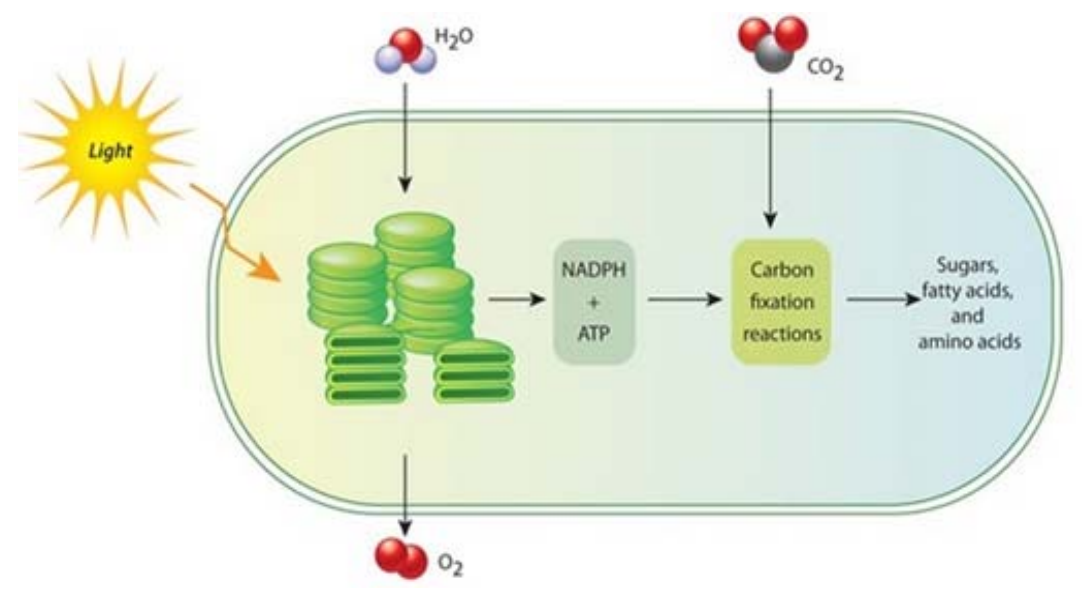

Fig. 3 Solar production of carbohydrates, amino acids through carbon fixation reactions.

Table 1 Solar electricity efficiencies of semiconductor metal oxide/dye cells.

\begin{tabular}{|c|c|c|c|c|c|}
\hline Semi-conductor & Dye & $\eta(\%)$ & Area $\left(\mathrm{cm}^{2}\right)$ & $\begin{array}{l}\text { Illumination } \\
\left(\mathrm{mW} / \mathrm{cm}^{2}\right)\end{array}$ & Reference \\
\hline \multirow[t]{2}{*}{$\mathrm{SnO}_{2} / \mathrm{ZnO}$} & N3 & 8 & 1.9 & 90 (“direct sunlight”) & Tennakone et al. 1999 \\
\hline & & 15 & & 10 (“diffuse daylight”) & \\
\hline \multirow[t]{2}{*}{$\mathrm{ZnO}$} & mercurochrome & 2.5 & 0.09 & 100 (AM1.5) & Hara et al. $2000 \mathrm{a}$ \\
\hline & & 1.4 & 0.25 & & \\
\hline $\mathrm{Nb}_{2} \mathrm{O}_{5}$ & N3 & 2 & 0.5 & 100 (AM1.5) & Sayama et al. 1998 \\
\hline $\mathrm{ZnO}$ & N3 & 2 & 0.25 & 56 (“solar simulator”) & Rensmo et al. 1997 \\
\hline
\end{tabular}




\section{Titania Solar Cell Structure}

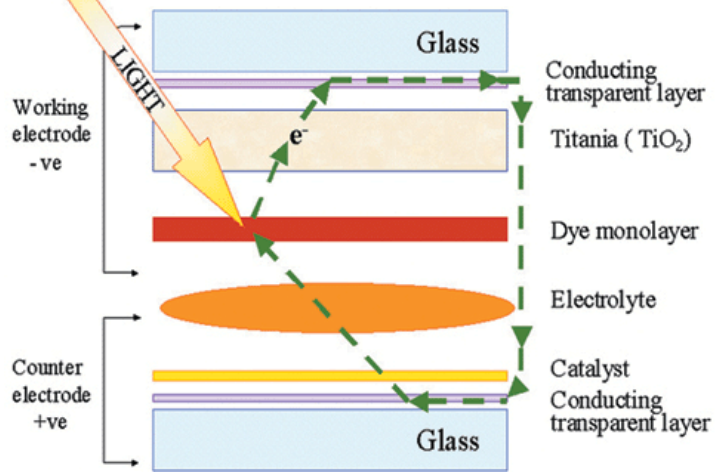

Fig. 4 Work function mechanism of an OPV (organic photo voltaic); Transparent Dye Sensitized Solar Cell-DSSC, constructed on a transparent conductive/ $/ \mathrm{TiO}_{2}$ layered glass.

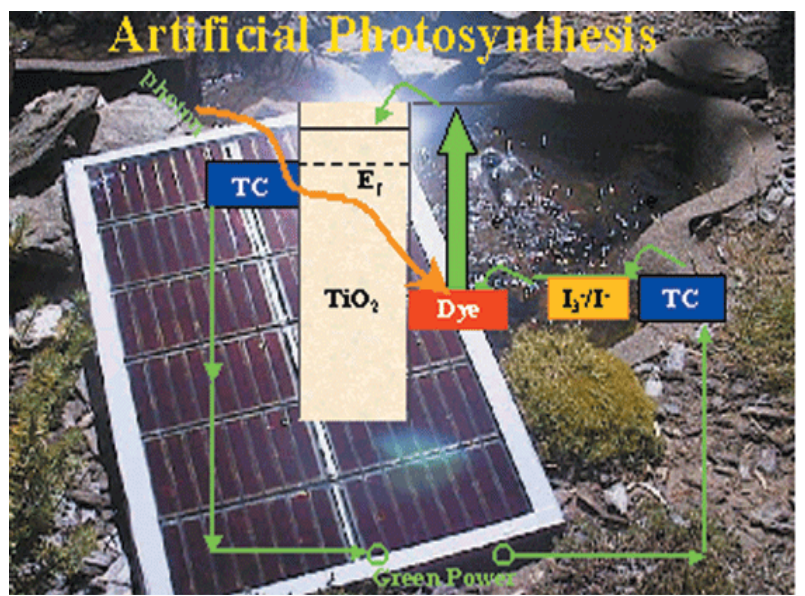

Fig. 5 Production of electricity by the reverse mechanism of photosynthesis, from a solar Si-crystal based Photo Voltaic-PV panel and by a $\mathrm{TiO}_{2} /$ dye based Organic Photo Voltaic-OPV panel.

near-infra-red utilization of the solar light, as of plants (Fig. 5).

At present, ruthenium complexes and metal porphyrins photosensitizers have an overall solar to energy conversion efficiency more than $12 \%$ for small area devices [3, 4]. However metal free organic dyes could be also considered as an alternative choice for the conversion of solar energy into electricity using DSSCs. TCO (Transparent conductive oxide) play an important role in the function of DSSCs and as well as OPVs (Fig. 6) [5-8]. The reason is that pure organic dyes have certain advantages over metal based photosensitizers: They are easily modified with common synthetic procedures while they exhibit high molar extinction coefficients compared to metal complexes. Organic dyes with high molar extinction coefficients could be advantageously used in thin titanium dioxide film based solar cells which are mainly required in solid state devices where the mass transport and pore filling are limited affecting the performance of the cells $[9,10]$.

\section{LEDs and OLEDs}

LEDs (light-emitting diodes) are the tiny, colored, indicator lights you see on electronic instrument panels.

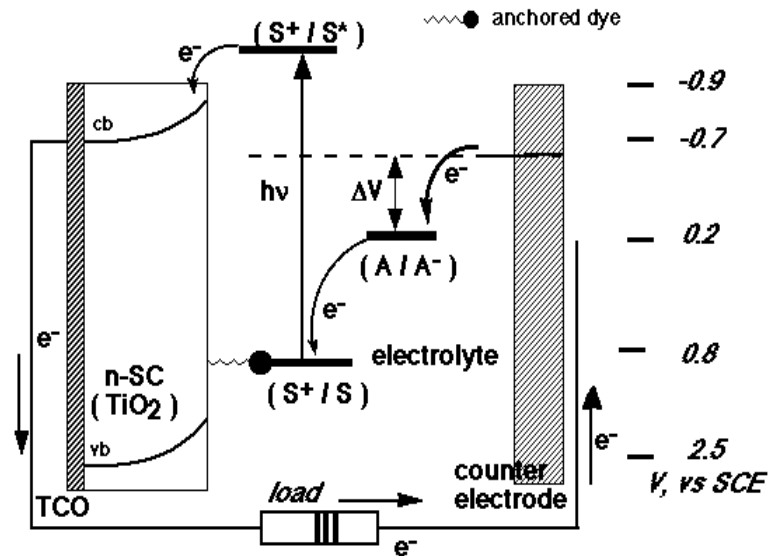

Fig. 6 Solar electricity efficiencies of semiconductor metal oxide/dye cells.

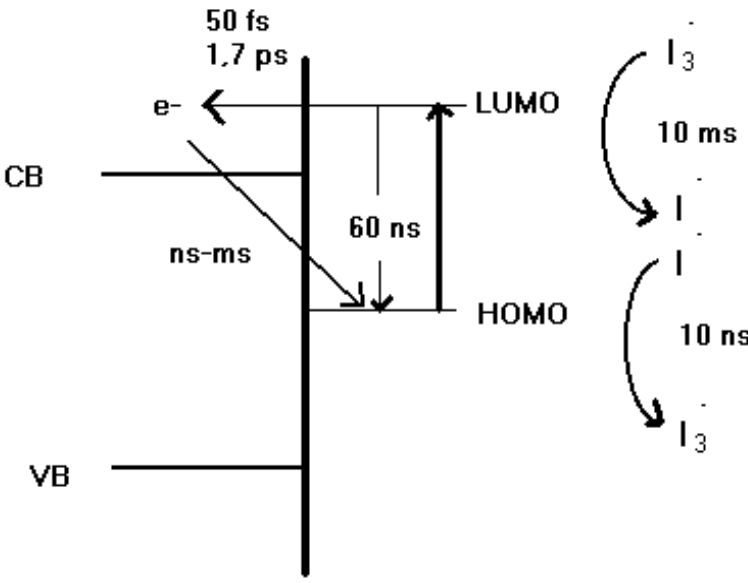

Semiconductor Dye Electrolyte

Fig. 7 Electron transfer mechanism of a semiconductor metal oxide/dye cell. 
<smiles>[R10]N1C(=O)c2ccc3c4ccc5c6c(ccc(c7ccc(c2c37)C1=O)c64)C(=O)N([R10])C5=O</smiles>

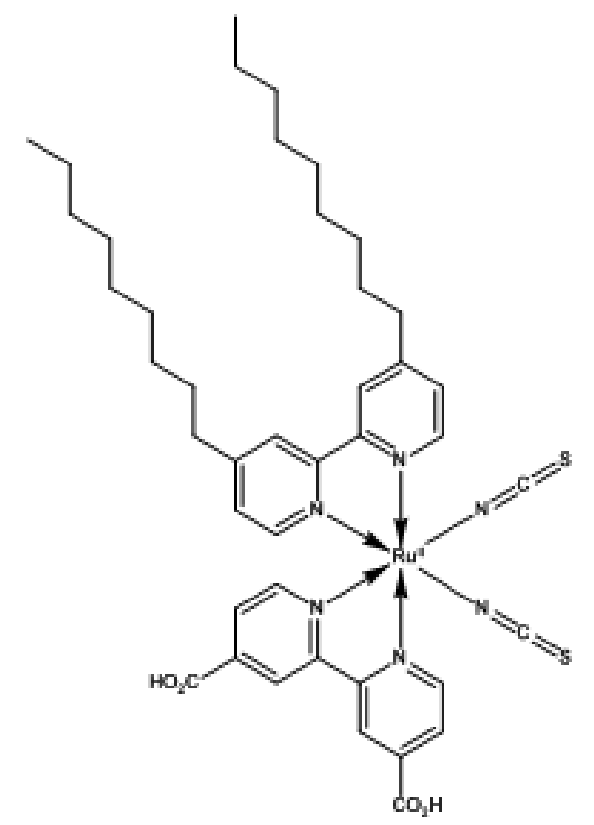

Fig. 8 Molecular structures of perylene di-imide derivatives and Ruthenium organic complex dyes as photosensors at organic photo-electronics.

They are much smaller, more energy-efficient, and more reliable than old-style incandescent lamps. Instead of making light by heating a wire filament till it glows white hot (which is how a normal lamp works), they give off light when electrons zap through the specially treated ("doped") solid materials from which they are made. An OLED is simply an LED where the light is produced ("emitted") by organic

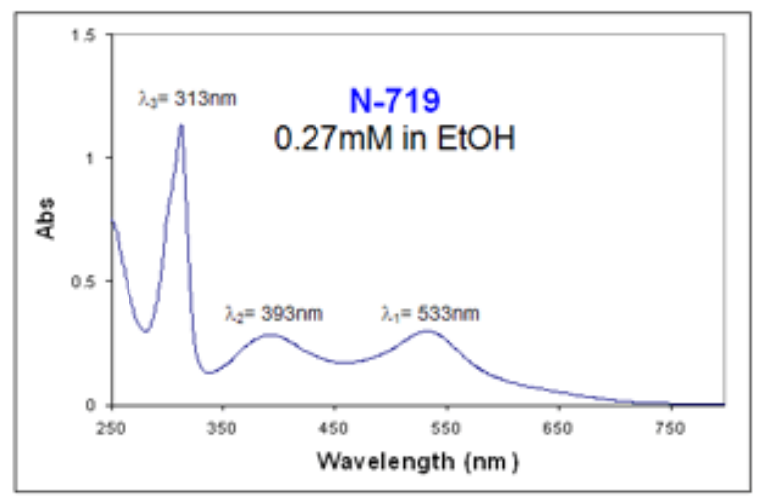

Fig. 10 UV absorption spectra of N-719 and Z-907 dyes. molecules. When people talk about organic things these days, they are usually referring to food and clothing produced in an environmentally friendly way without the use of pesticides. But when it comes to the chemistry of how molecules are made, the word has a completely different meaning. Organic molecules are simply ones based around lines or rings of carbon atoms, including such common things as sugar, gasoline, alcohol, wood, and plastics.

OLEDs, Organic electronics are still a young area of technology that comprises applications as diverse as illuminants, photovoltaics, printed electronics and batteries. Replacing inorganic by organic materials, in particular conversion of light to electrical current (photovoltaics) and electrical current to light (light diodes), are promising basic economic and ecological benefits as well as benefits regarding application options and design, e.g. for large-area lighting, flexible

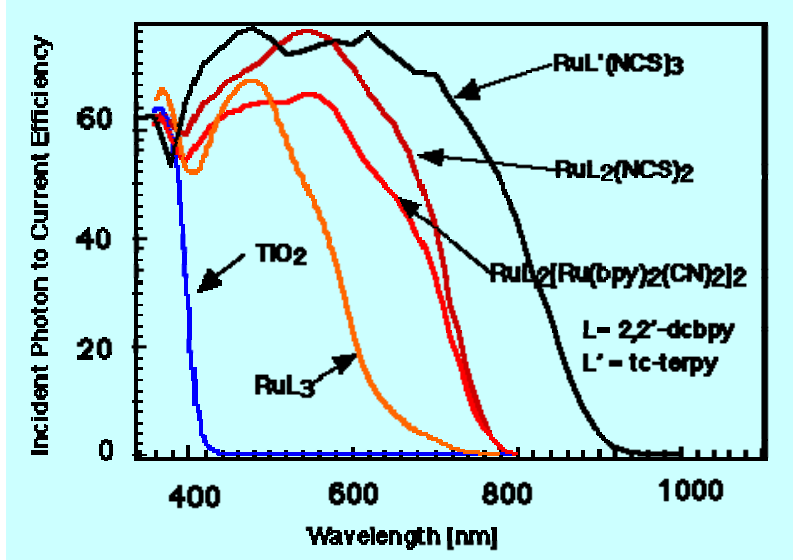

Fig. 9 Incident photon to current efficiency and absorption wavelengths grafic of rutenium dyes. As seen Ru-dyes absorb efficiently under solar irradiation.

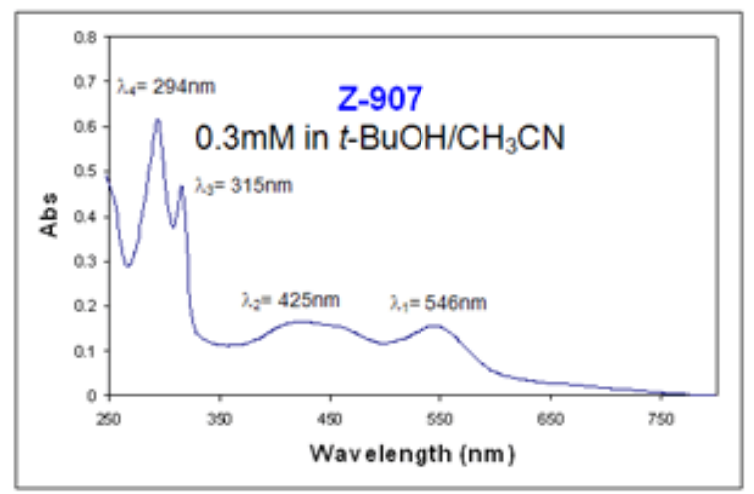


Table 2 Efficiencies of organic solar cell types based on $\mathrm{TiO}_{2}$ semiconductor, from literature.

\begin{tabular}{|c|c|c|c|c|c|}
\hline Semi-conductor & Dye & $\eta(\%)$ & Area $\left(\mathrm{cm}^{2}\right)$ & $\begin{array}{l}\text { Illumination } \\
\left(\mathrm{mW} / \mathrm{cm}^{2}\right)\end{array}$ & Reference \\
\hline$\overline{\mathrm{TiO}_{2}}$ & $?$ & 11 & 0.25 & 100 (AM1.5) & Green 2001 \\
\hline $\mathrm{TiO}_{2}$ & Black dye & 10.4 & $?$ & $100(\mathrm{AM} 1.5)$ & Gratzel 2000 \\
\hline $\mathrm{TiO}_{2}$ & N3 & 10.0 & 0.3 & $96(\mathrm{AM} 1.5)$ & Nazeeruddin et al. 1993 \\
\hline $\mathrm{TiO}_{2}$ & $\mathrm{~N} 719^{22}$ & 9.2 & 1.5 & $?(\mathrm{AM} 1.5)$ & Deb et al. 1998 \\
\hline $\mathrm{TiO}_{2}$ & $\operatorname{RuL}_{2}\left(\mu-(\mathrm{CN}) \operatorname{Ru}(\mathrm{CN}) \mathrm{L},{ }_{2}\right)_{2}$ & $\begin{array}{l}7.1 \\
7.9\end{array}$ & 0.5 & $\begin{array}{l}75 \text { (AM1.5) } \\
8 \text { (AM1.5) }\end{array}$ & O’Regan \& Gratzel 1991 \\
\hline $\mathrm{TiO}_{2}$ & N3 & $\begin{array}{l}6 \\
7.3\end{array}$ & 1 & $\begin{array}{l}100 \text { (ELH lamp) } \\
11.5 \text { (ELH lamp) }\end{array}$ & Hagfeldt et al. 1994 \\
\hline $\mathrm{TiO}_{2}$ & $\begin{array}{l}\text { A Ru-phenantroline } \\
\text { derivative }\end{array}$ & 6.1 & 0.44 & 100 (AM1.5) & Yanagida et al. 2000 \\
\hline $\mathrm{TiO}_{2}$ & A coumarin derivative & 5.6 & $?$ & $100(\mathrm{AM} 1.5)$ & Hara et al. 2001a \\
\hline $\mathrm{TiO}_{2}$ & $\mathrm{Cu}$-2- $\alpha$-oxymesousochlorin & 2.6 & 0.5 & 100 ("white light") & Kay \& Gratzel 1993 \\
\hline $\mathrm{TiO}_{2}$ & A natural cyanin-dye & 0.56 & 0.9 & $100(\mathrm{AM} 1.5)$ & Cherepy et al. 1997 \\
\hline
\end{tabular}

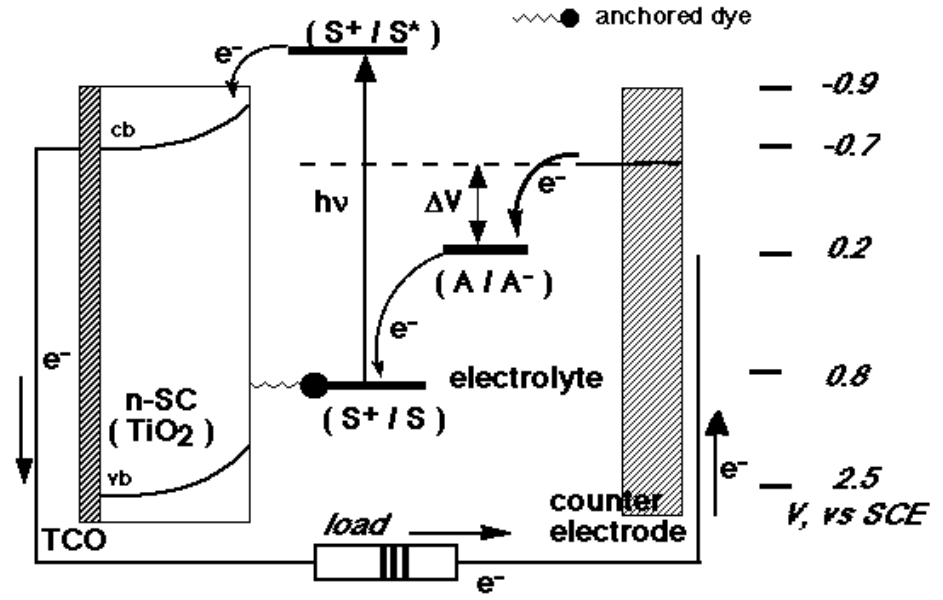

(a)

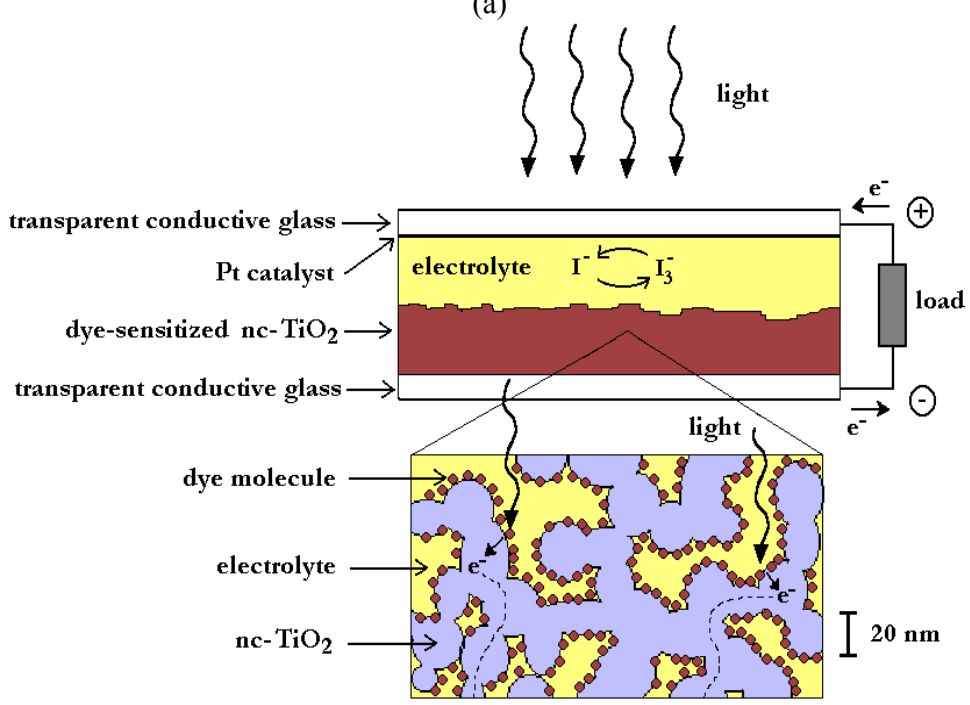

(b)

Fig. 11 The work mechanism (a) and function (b) of a Organic Photo Voltaic-OPV-Dye Sensitized Solar Cell. 
displays and generation of energy" [ACA-11]. OLEDs (Organic light emitting diodes) are promising candidates for general illumination, too, since they offer the possibility to realize large area light sources which can even be transparent and flexible. The energy-saving potential of OLEDs is similar to that of LEDs, but the two technologies differ in a number of ways. The following tables 1 and 2 compare LED and OLED technologies. An OLED is an LED (light-emitting diode) in which the emissive electroluminescent layer is a film of organic compound that emits light in response to an electric current (Fig. 13). OLEDs are used to create digital displays in devices such as television screens, computer monitors, portable systems such as mobile phones, handheld game consoles and PDAs. A major area of research is the development of white OLED devices for use in solid-state lighting applications. While there has recently been a dramatic expansion in the use of OLEDs for displays, a direct impact on the cost of OLED lighting products is not yet evident. Partly this is because OLED lighting manufacturing is still evolving and the device architectures and performance requirements are different from those for displays. Nevertheless, today several OLED products for general lighting are already available.

OLEDs offer yet another light source technology with unique spectral power densities. The broad spectrum of OLED emission peaks allows for full coverage of the visible spectrum; however, red emission in the infrared regime and the lack of efficient, long-life blue emitters limit options in terms of optimizing the trade-off between colour quality and efficacy. Most OLED panels emit light over a complete hemisphere, with a distribution close to Lambertian, this is a fundamental difference from other lighting technology. Unlike existing light sources, such as incandescent light bulbs and fluorescent lamps, OLEDs are planar light emitters that are lightweight and have thin profiles. This allows lamp manufacturers and designers to create unprecedented designs and provide dramatic effects, leading to the creation of new living environments in houses, offices, stores, and vehicles such as cars and airplanes. In principle, OLEDs emit UV-free "pleasant light" with a high CRI (Colour Rendering Index). An OLED device with broad spectrum can achieve a radiant efficacy 1 as high as $325 \mathrm{~lm} / \mathrm{W}$ and, possibly, this value can go up to $400 \mathrm{~lm} / \mathrm{W}$.

However, an early Nano Marker white paper pointed-out that Organic electronics is in no position to replace silicon, but there are many applications for which organic materials currently offer a competitive or superior mix of performance and economics, their number is growing, and the opportunity for materials firms is substantial.

\subsection{Basics of the OLED Technology}

An OLED is a solid-state device consisting of a thin, carbon-based semiconductor layer that emits light when electricity is applied by adjacent electrodes. In order for light to escape from the device, at least one of the electrodes must be transparent. The intensity of the light emitted is controlled by the amount of electric current applied by the electrodes, and the light's colour is determined by the type of emissive material used.

The basic structure of an OLED consists of a thin film of organic material (typical thickness in the order of $100 \mathrm{~nm}$ ) sandwiched between two electrodes, all

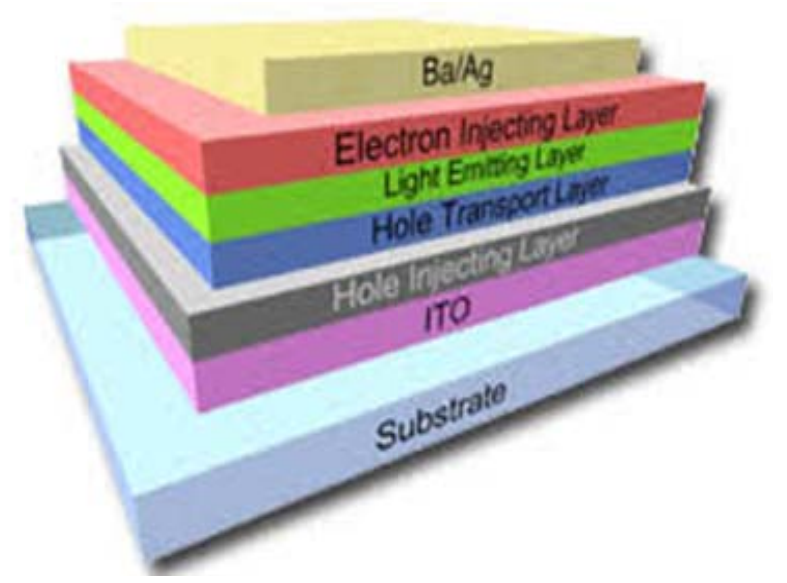

Fig. 12 Typical structure of an OLED. 
deposited on a substrate. There are two different types of OLED. Traditional OLEDs use small organic molecules deposited on glass to produce light. The other type of OLED uses large plastic molecules called polymers. Those OLEDs are called LEPs (light-emitting polymers) or, sometimes, PLEDs (polymer LEDs). Since they are printed onto plastic (often using a modified, high-precision version of an inkjet printer) rather than on glass, they are thinner and more flexible. OLED displays can be built in various different ways. In some designs, light is designed to emerge from the glass seal at the top; others send their light through the substrate at the bottom. Large displays also differ in the way pixels are built up from individual OLED elements. In some, the red, green, and blue pixels are arranged side by side; in others, the pixels are stacked on top of one another so you get more pixels packed into each square centimeter/inch of display and higher resolution (though the display is correspondingly thicker).

\subsection{Advantages and Disadvantages of OLEDs}

Today, different stack structures are possible: Bottom or top emission (Fig. 12): Bottom or top distinction refers not to orientation of the OLED display, but to the direction that emitted light exits the device. OLED devices are classified as bottom emission devices, if emitted-light pass through the transparent or semi-transparent bottom electrode and substrate on which the panel was manufactured.

Top emission devices are classified based on whether or not the light emitted from the OLED device exits through the lid that is added following fabrication of the device. Radiant efficacy is defined as the ratio between emitted the luminous flux $(\mathrm{lm})$ over the emitted power (W) across all wavelengths.

The transparent or semi-transparent OLEDs-TOLEDs have contacts on both sides of the device to create displays that can be made to be both top and bottom emitting. TOLEDs can greatly improve contrast, making it much easier to view displays in bright sunlight. This technology can be used in Head-up displays, smart windows or augmented reality applications. TOLED is a breakthrough transparent display technology that displays dynamic or interactive information on a transparent surface glass. This revolutionary display allows users to view what is shown on a glass video screen while still being able to see through it. Designers can overlay text, digital images, and video content onto physical objects or scenes that sit behind the glass. TOLED displays are self-emitting and utilize

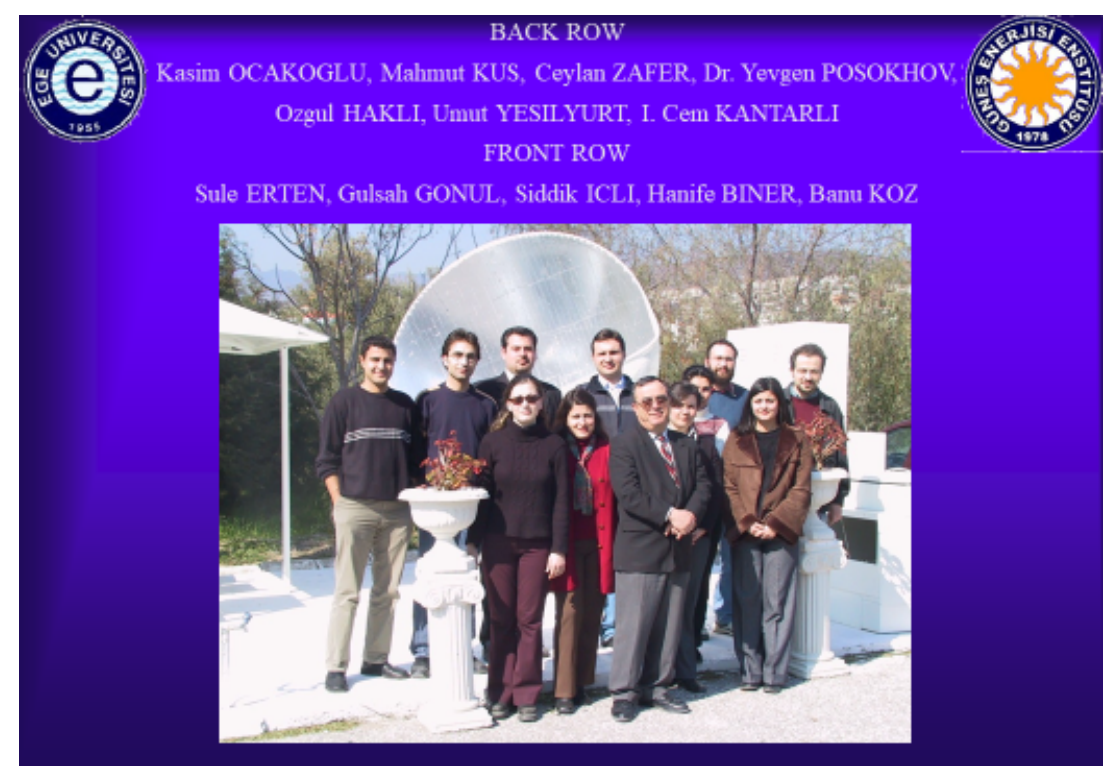

Fig. 13 Research group of Prof. Dr. Siddik Icli at solar energy Institute of Ege Univesity in 2003. Most of the researchers are now professors/researchers at Universities in Turkey and Ukraine. 
cutting-edge OLED (Organic Light Emitting Diode) technology to eliminate the need for a backlight or enclosure, making it possible to create truly see-through installations in a virtually frameless glass design. Each pixel in a TOLED display is made up of 4 sub-pixels. Color is created by the combination of the red, green, and blue sub-pixels and the remaining area of the pixel is clear. That clear section creates the transparency.

This is why there is a direct relationship between resolution and transparency. If the display contains more active pixels that create less space for the clear pixels and result in a display that is less seen through.

Organic electroluminescent materials, based on $\pi$-conjugated molecules may be electrically conductive as a result of delocalization of $\pi$-electrons caused by conjugation over part or the entire molecule. These materials have conductivity levels ranging from insulators to conductors, and are therefore considered as organic semiconductors. In organic semiconductors the highest occupied and lowest unoccupied molecular orbitals (HOMO and LUMO) of organic semiconductors are analogous to the valence and conduction bands of inorganic semiconductors. During operation, a voltage is applied across the OLED such that the anode is positive with respect to the cathode. A current of electrons flows through the device from cathode to anode, as electrons are injected into the LUMO of the organic layer at the cathode and withdrawn from the HOMO at the anode. This latter process may also be described as the injection of electron holes into the HOMO. Electrostatic forces bring the electrons and the holes towards each other and they recombine forming an exciton, a bound state of the electron and hole. This happens closer to the emissive layer, because in organic semiconductors holes are generally more mobile than electrons. The decay of this excited state results in a relaxation of the energy levels of the electron, accompanied by emission of radiation whose frequency is in the visible region. The wavelength depends on the band gap of the material, in this case the difference in energy between the HOMO and LUMO. An OLED emits almost monochromatic radiation.

White OLED (WOLED) lighting devices are designed to achieve a white colour by simultaneously emitting light from organic substances that radiate in colours such as blue, red, and green. However, changes in lighting colours due to aging (colour shift) are inevitable because the durability of devices differs from colour to colour. This is an issue that must be addressed in addition to the issue of luminance lifetime.

As for any emerging technology, a large variety of materials and OLED structures are used in production or tested. Moreover, alternatives to existing materials are still actively researched in order to improve the light performance, lifetime, and decreased manufacturing costs. There are two main families of organic light emitting materials: those based on small molecules and those employing polymers. The polymer technology is usually called "Polymer light-emitting diodes"-PLED.

Fluorescent dyes can be chosen to obtain light emission at different wavelengths, and compounds such as perylene, rubrene and quinacridone derivatives are often used. Phosphorescent organic light emitting diodes use the principle of electrophosphorescence to convert electrical energy in an OLED into light in a highly efficient manner, with the internal quantum efficiencies of such devices approaching $100 \%$ when fluorescent materials are strictly limited to $25 \%$. The termed Ph-OLED applies to this category of molecules. Small molecules dominate the only sizeable market in organic electronics to date OLEDs. However, they suffer a serious drawback: they are difficult to make into inks. Because fabrication by printing is one of the key selling points of organic electronics, the issue clearly has commercial importance.

PLEDs (Polymer light-emitting diodes), involve an electroluminescent conductive polymer that emits 
light when connected to an external voltage. They are used as a thin film for full spectrum colour displays. Polymer OLEDs are quite efficient and require a relatively small amount of power for the amount of light produced. Polymers are easily solubilized and relatively easy to make into inks for printable electronics applications. High-molecular-weight materials, they consist of long chains of repeating molecular units that offer many opportunities for the control of electronic, chemical, morphological and rheological properties.

Although the uncertainty about the future winning material approach between small molecule OLED materials and polymer materials remains, polymers continue to struggle to demonstrate the ability turning their cost and performance potential into an industrial reality. Today, the rate of lumen depreciation of red and green emitters has been reduced to acceptable levels, but significant improvements are necessary for phosphorescent blue emitters.

Oligomers are short-chain polymers with well-defined molecular characteristics. They are usually prepared step-wise, so that the exact chain length is well known. As low-molecular weight polymers, they generally have properties that are between those of small molecules and polymers. In many cases, they can offer the advantages of both types of materials simultaneously. For example, some oligomers are both sufficiently soluble to be deposited from solution, and sufficiently volatile to be vacuum deposited. At the present time, however, there does not seem to be many attempts to commercialize oligomers for electronic applications.

Organic/inorganic hybrids: Hybrid materials are becoming increasingly important. Many so-called organic electronic products are already a kind of "hybrid," in that inorganic materials are often used as conductors and for dielectrics, but hybrid materials combine the two more intimately, the objective being to improve the performance parameters of organic electronics while maintaining its characteristic advantages. Often hybrids supply higher mobility/conductivity, which can be achieved with the addition of carbon nanotubes, nanorods or fullerenes.

Adding mobile ions to an OLED creates an LEC (light-emitting electrochemical cell) that has a slightly different mode of operation. It is also possible to create OLEFETs (Organic Light Emitting Field Effect Transistors). OLEFETs are three-terminal devices (Drain, Source, and Gate) where the current is modulated by the gate voltage. Small molecules or polymers are used in semiconductor layer and dielectric layer.

Unlike OLEDs the light emission intensity can be modulated by the gate and drain voltage. Concerning substrates, rigid glass maintains its exclusivity as a substrate material in OLED lighting panel production. However, progress has been made in the development of techniques, such as roll-to-roll processing, the development of flexible ultra-thin glass and flexible encapsulation solutions that will enable the progressive penetration of flexible OLED panels into the lighting market [YOL-12]. Plastics substrate major challenges, esp. thermal expansion, stability, temperature limits for processing, among others. Introduction of OLEDs on flexible substrates and the application of roll-to-roll manufacturing methods are however delayed due to several drawbacks. By far the most challenging problem in this respect is the development of reliable barriers to prevent ingress of water and oxygen through plastic substrates and covers. Though in the near-term, competitive OLED lighting devices will likely be made using vacuum deposition or hybrid (combination of solution and evaporated layers) approaches, many of the proposed methods to reduce manufacturing costs involve the replacement of vacuum deposition methods by solution processing. This requires the development of new materials that initially exhibited much poorer performance in both efficacy and lifetime. Despite considerable effort in recent years by companies such 
as CDT, DuPont, and Merck, there is still a performance gap. The typical efficacy is lower by at least $50 \%$.

\subsection{Evolution of the OLED Technology and Targets}

The electroluminescence, "the emission of electromagnetic radiation from condensed matter subjected to an external electric field", from a thracene (organic material) has been discovered in 1963. A. Hegger, A. McDiarmid and S. Shurakawa explained the possibility to obtain conductive organic thin films using $\pi$-conjugated materials (polyacetylene) used organic hetero structures to demonstrate the first OLED diode in 1987. Researchers from Cambridge (UK) who demonstrated in 1990 the possibility to use conjugated way to light production from organic materials were open chemists of Ching W. Tang and Steven Van Slyke, researchers at the Eastman Kodak Corporation. In the early 2000s, researchers at Pacific Northwest National Laboratory and the Department of Energy invented two technologies necessary to make flexible OLEDs: first, Flexible Glass an engineered substrate that provides a flexible surface, and second, a Barix thin film coating that protects a flexible display from harmful air and moisture. Initially, due to the moderate thickness of the vacuum-evaporated layers $(\approx 100 \mathrm{~nm})$, light emission at rather low driving voltages $(\approx 5 \mathrm{~V})$ was achieved with an EQE (external quantum efficiency) of about $1 \%$. The first polymer OLED fabricated by spin coating had even worse characteristics: $\mathrm{EQE}$ of about $0.05 \%$ at driving voltages of about $15 \mathrm{~V}$. Since these first steps, considerable progress has been achieved in improving the performances of OLEDs as well as in studying the basic physics of such devices.

The first applications of OLEDs appeared at around 1997 with small monochrome displays for car radios. Nowadays, about 20 years after their first demonstration, OLEDs are seen as promising candidates for the next generation of display and lighting applications. Impressive numbers have been published on white OLEDs under laboratory conditions: a device with a luminous efficacy in excess of $120 \mathrm{~lm} / \mathrm{W}$ devices with 34\% EQE, as well as devices with CRIs greater than 90 and lifetimes in excess of $30,000 \mathrm{~h}$ at a luminance of $5,000 \mathrm{~cd} / \mathrm{m}^{2}$ have been demonstrated by A. Hegger, A. McDiarmid and S. Shurakawa, obtained in 2000 the Nobel for chemistry thanks to this discovery at the time of their publication. UDC (Universal Display Corporation) has steadily achieved records in luminous efficacy, at the "pixel" and the commercial-sized "panel" scales. Funded in part by the USD department of Energy, these advances now meet a variety of niche performance targets and move white OLEDs closer to general lighting targets set by US DoE. As example, UDC has successfully demonstrated in 2008 a record-breaking white organic lightemittingdiode (WOLED) with a power efficacy of $102 \mathrm{~lm} / \mathrm{W}$ at $1,000 \mathrm{~cd} / \mathrm{m}^{2}$ using its proprietary, high-efficiency phosphorescent OLED technology.

Highly efficient, large-area prototype OLED panels have been recently demonstrated. Konica Minolta has shown a $15 \mathrm{~cm}^{2}$ panel with an efficacy of $131 \mathrm{~lm} / \mathrm{W}$ at $1,000 \mathrm{~cd} / \mathrm{m}^{2}$ and $118 \mathrm{~lm} / \mathrm{W}$ at $3,000 \mathrm{~cd} / \mathrm{m}^{2}$. Panasonic has successfully scaled their technology to an area of $25 \mathrm{~cm}^{2}$, achieving efficacy of $112 \mathrm{~lm} / \mathrm{W}$ at 1,000 $\mathrm{cd} / \mathrm{m}^{2}$ and $98 \mathrm{~lm} / \mathrm{W}$ at $3,000 \mathrm{~cd} / \mathrm{m}^{2}$. Lumen maintenance (L50) for both panels is acceptable at 55,000 hours for the Konica Minolta panel and over 100,000 hours for the Panasonic panel when operated at $1,000 \mathrm{~cd} / \mathrm{m}^{2}$. These high-efficacy prototypes are promising, but as with LEDs, maximizing the efficacy of an OLED panel must be balanced against other important characteristics, such as lifetime, colour quality, cost, and form factor. OLED Marke at the early time of OLED technology was targeting displays and small screens for nomad applications. In this context, PMOLED started shipments in 1999, AMOLED started at the end of 2002. Kodak DSC easy share was the first AMOLED in market. The market evolution was at those beginning stages. 
OLED display revenues will grow to about $\$ 44$ billion in 2019 , up from a total product revenue: $\sim \$ 826$ million in 2009 ( $\sim 73$ million units shipped) and \$4 billion in 2011, with CAGR $\sim 40 \%$. Mobile phone main display saw strong growth recently and will continue to lead in revenue for the next several years.

The first OLED lighting products have become commercially available in 2009: "Lumiblade" from Philips and the "ORBEOS" from OSRAM. The latter features an active area of $100 \mathrm{~cm}^{2}$ at a thickness of 2.1 $\mathrm{mm}$ and a weight of $24 \mathrm{~g}$, a luminous efficacy of about $25 \mathrm{~lm} / \mathrm{W}$ at $1,000 \mathrm{~cd} / \mathrm{m}^{2}$, a CRI of 75 , and a median lifetime up to $15,000 \mathrm{~h}$. During 2011, the potential that OLED technology brings in innovative luminaire design has been confirmed with many new concepts shown on company websites, at exhibitions and in high profile promotional installations. J. N. Bardsley reported in 2011that new products are yet in the market with light output in the order of $12 \mathrm{~lm}$ corresponding to luminous efficacy of $45 \mathrm{~lm} / \mathrm{W}$, thickness of $1.8 \mathrm{~mm}$, luminance of $10,000 \mathrm{~cd} / \mathrm{m}^{2}, \mathrm{CCT}$ $2,800 \mathrm{~K}$ and lifespan of $10,000 \mathrm{~h}$ and price of $\$ 175$ ( $\$ 14,500$ perkilolumen). The Korean semiconductor equipment maker Jusung Engineering released today an OLED lighting panel with a size of $730 \times 920 \mathrm{~mm}$ which is deposited on glass substrates. The availability of high-efficacy panels has allowed luminaire manufacturers such as acuity to focus on improvements in colour quality and lifetime, offering CRI of $89, \mathrm{CCT}$ at $3,000 \mathrm{~K}$, and lumen maintenance (L70) at 18,000 hours from $3,000 \mathrm{~cd} / \mathrm{m}^{2}$. Progress has also been made on reducing panel-to-panel colour variations to around four standard deviations in colour matching in luminaires with multiplepanels.

\section{References}

[1] Razeghifard, R. 2013. Natural and Artificial Photosynthesis. Wiley ISBN: 978-1-118-16006-0 (Nov. 2013).

[2] Pope, M., Kallman, H. P., and Magnante, P. J. 1963. "Electroluminescence in Organic Crystals." J. Chem. Phys. 38: 2042-3.

[3] Havare, A. K., Can, M., Tozlu, C., Kus, M., Okur, S., Demic, Ş., Demirak, K., and Kurt, M. 2016. "Charge Transfer through Amino Groups-Small Molecules Interface Improving the Performance of Electroluminescent Devices." Optical Materials 55: 94-101.

[4] Sas, E. B., Kurt, M., Can, M., Okur, S., İçli, S., and Demic, S. 2014. "Structural Investigation of a Self-assembled Monolayer Material 5-[(3-Methylphenyl) (Phenyl) Amino] Isophthalic Acid for Organic Light-Emitting Devices." Spectrochimica Acta Part A: Molecular and Biomolecular Spectroscopy 133 (20): 307-17.

[5] Singh, B., Erten, S., Sarıçiftçi, N. S., Icli, S., Teoman, Y., Kuban, B., T. Sise Cam Fabrikaları, A. S. 2005. "Peryleneimide/Dimide Based OFETs and a Method of Producing the Same." Appl. No/Patent No: 05709076.3-1235, PCT/ IB2005/50997.

[6] Zissis, G., and Bertoldi, P. 2014. "2014 Status Report on Organic Light Emitting Diodes-OLED.” European Commission-JRC Science and Policy Reports.

[7] Hagberg, D. P., Marinado, T., Karlsson, K. M., Nonomura, K., Qin, P., Boschloo, G., Brinck, T., Hagfeldt, A., and Sun, L. 2007. "Tuning the HOMO and LUMO Energy Levels of Organic Chromophores for Dye Sensitized Solar Cells.” Journal of Organic Chemistry 72: 9550-6.

[8] Gao, F., Wang, Y., Shi, D., Zhang, J., Wang, M., Jing, X., Humphry-Baker, R., Wang, P., Zakeeruddin, S. M., and Gratzel, M. 2008. "Enhance the Optical Absorptivity of Nanocrystalline $\mathrm{TiO}_{2}$ Film with High Molar Extinction Coefficient Ruthenium Sensitizers for High Performance Dye-Sensitized Solar Cells." Journal of the American Chemical Society 130: 10720-8.

[9] Arakawa, H. 2002. Petrotech 25: 179-82.

[10] Cook, B. 2013. "The Important Role of Photosynthesis." Michigan State University Extension, accessed on April 9, 2013. Available at: http://www.msue.msu.edu. 